\title{
Ampicillin Inactivation and Sensitivity of Coliform Bacilli
}

\author{
By G. A. J. AYLIFFE \\ Department of Bacteriology, Postgraduate Medical School of \\ London, Ducane Road, London, W. 12
}

(Received 14 June 1962)

\begin{abstract}
SUMMARY
Ampicillin sensitivity tests and tests for ampicillin inactivation were made with 148 strains of coliform bacilli. A correlation was found in strains of Proteus mirabilis and Klebsiella between ampicillin resistance and inactivation. No correlation was obtained with Escherichia coli, whether sensitive or resistant to ampicillin, although small amounts of penicillinase were produced. Ampicillin-sensitive strains of $\boldsymbol{P}$. mirabilis showed even lower amounts of penicillinase. The strains of Pseudomonas pyocyanea (aeruginosa) were resistant to ampicillin, but also showed low penicillinase levels. No evidence of induction of penicillinase was obtained with $E$. coli or Klebsiella in the presence of methicillin, ampicillin or cephalosporin C. The ampicillin-inactivating enzyme is a $\beta$-lactamase, not an amidase. Resistance of ampicillin-sensitive strains of $E$. coli was increased rapidly by serial subcultures but was not associated with higher penicillinase values. Ampicillin was inactivated less rapidly than was benzylpenicillin by penicillinase from an $E$. coli strain.
\end{abstract}

\section{INTRODUCTION}

Many strains of coliform bacilli have been shown to be sensitive to low concentrations of the new penicillin, ampicillin $6(\mathrm{D}(-) \alpha$-aminophenylacetamido $)$ : penicillanic acid ('Penbritin; Rolinson \& Stevens, 1961; Stewart, Coles, Nixon \& Holt, 1961; Brumfitt, Percival \& Carter, 1962). Nevertheless, in early studies with benzylpenicillin, it was shown that most species of coliform bacilli produced a 'penicillinase' (Abraham \& Chain, 1940; Harper, 1943; Woodruff \& Foster, 1945; Bondi \& Dietz, 1944; Czekalowski, 1950) and ampicillin has been shown to be fully sensitive to the penicillinase produced by penicillin-resistant staphylococci. It was therefore decided to investigate the relationship between penicillin inactivation and ampicillin sensitivity in coliform bacilli.

The terminology of penicillin-inactivating enzymes now needs some clarification since the enzymes may attack the penicillin molecule in at least two different sites, i.e. by splitting the $\beta$-lactam ring or by removing the side chain. In the present paper the term penicillinase will be reserved for enzymes splitting the $\beta$-lactam ring and the term amidase used for enzymes removing the side chain. When a penicillinase acts on penicillin and splits the $\beta$-lactam ring, penicilloic acid is formed. Although penicilloic acids derived from benzylpenicillin and ampicillin differ, they both reduce iodine to the same extent and are therefore referred to in the text as 'penicilloic acids'. 


\section{METHODS}

Ampicillin sensitivity. Coliform type organisms (148 strains) were identified and tested for sensitivity to ampicillin. The sensitivity of the organisms was determined by the ditch plate method, the ditches containing $\mathbf{5 0} \mu \mathrm{g}$. ampicillin $/ \mathrm{ml}$. A standard strain of Escherichia coli sensitive to $3 \mu \mathrm{g}$. ampicillin $/ \mathrm{ml}$. was used as a control. The results were recorded as sensitive, partially resistant or resistant as compared with the control organism. Six strains each of ampicillin-sensitive $E$. coli and Proteus mirabilis were tested by the broth dilution method to determine the range of minimum inhibitory concentrations of ampicillin-sensitive strains.

\section{Ampicillin and benzylpenicillin inactivation}

Cup-plate assay. A screening test for ampicillin inactivation was performed on the organisms tested for ampicillin sensitivity. Ampicillin was added to $5 \mathrm{ml}$. of a $6 \mathrm{hr}$. shaken broth culture to a final concentration of $100 \mu \mathrm{g} . / \mathrm{ml}$. After a further $18 \mathrm{hr}$. of incubation at $37^{\circ}$ without shaking, the cultures were examined for residual ampicillin by the cup-plate assay method. The results were recorded as complete inactivation, partial or no inactivation. This test did not detect low degrees of ampicillin inactivation and some of the organisms which showed no inactivation were further tested by incubation with a lower concentration of ampicillin (20 $\mu \mathrm{g}$.) ml.). Samples were removed at 1, 3, 6 and $18 \mathrm{hr}$. and again tested for residual ampicillin by the cup-plate method. Similar tests were performed on three strains of Pseudomonas pyocyanea (aeruginosa) and four strains of ampicillin-sensitive Proteus mirabilis. A strain of Klebsiella and broth containing antibiotic only were used, as positive and negative controls respectively.

Iodometric method. Penicillinase was estimated by the iodometric method of Perret (1954). This test depends on the hydrolysis of the various penicillins to their respective penicilloic acids by penicillinase. Iodine is reduced by penicilloic acids and approximately eight equivalents iodine are equivalent to 1 mole penicilloic acid. In the test samples $(0 \cdot 5-2 \mathrm{ml}$.) of an overnight shaken broth culture were added to $5 \mathrm{ml}$. of a benzylpenicillin solution ( $0.25 \mathrm{~g}$. of benzylpenicillin in $100 \mathrm{ml}$. of phosphate buffer, $\mathrm{pH} \mathrm{6.8)}$ and shaken at $37^{\circ}$ for 1-5 hr., depending on the rate of formation of penicilloic acid by the organism concerned. Six strains of Escherichia coli, two strains of Citrobacter freundii, six strains of Klebsiella, fourteen strains of Proteus, also a strain of a penicillinase-producing staphylococcus and a non-penicillinaseproducing staphylococcus were tested by this method.

Effect of $\mathrm{pH}$ values on penicillinase activity. Penicillinase activity was estimated by the iodometric method, using $6 \mathrm{hr}$. shaken broth cultures of a strain each of Klebsiella, Proteus vulgaris and Escherichia coli. Two ml. of broth culture from each organism were incubated with penicillin in a series of phosphate buffers of $\mathrm{pH}$ range $4 \cdot 5-8 \cdot 0$.

Penicillinase induction. The strains of coliform bacilli examined were shaken in broth for $6 \mathrm{hr}$. at $37^{\circ}$ to which ampicillin, methicillin or cephalosporin $\mathrm{C}$ had been added to a final concentration of $2 \mu \mathrm{g} . / \mathrm{ml}$. Penicillinase was estimated by the iodometric and cup-plate assay methods.

Penicillin amidase production. Penicillin amidase removes the side-chain from the penicillin molecule and leaves the $\beta$-lactam ring intact. The product is 6-amino- 
penicillanic acid (6-APA) and was tested for by a modification of the hole-plate method described by Uri \& Sztaricskai (1961). Phenylacetyl chloride and sodium carbonate were added to the test fluid in a Heatley cup placed on a nutrient agar plate seeded with a culture of the Oxford staphylococcus, and incubated overnight at $30^{\circ}$. When 6 -APA is present it is converted into benzylpenicillin by the phenylacetyl chloride and a zone of inhibition is shown. Controls without phenylacetyl chloride were set up, and also a control containing a known amount of 6-APA. 109 broth cultures of coliform bacilli were tested by this technique.

Since penicillin amidase is mainly intracellular, and has an optimum activity at pH 7.5-8.5 (Rolinson et al. 1960) further tests were made with two strains of an ampicillin-resistant Escherichia coli, two strains of an ampicillin-sensitive $E$. coli, a strain of ampicillin-resistant Klebsiella and a control organism known to produce the amidase. These organisms were grown in shaken broth cultures in a water bath at $28-30^{\circ}$ for $24 \mathrm{hr}$. The cultures were then centrifuged and the deposited organisms resuspended in phosphate buffer $(\mathrm{pH} \mathrm{8.0)}$ and incubated with benzylpenicillin for periods from $15 \mathrm{~min}$. to $24 \mathrm{hr}$. at $30^{\circ}$ or $37^{\circ}$. Tests were made for 6-APA by the above method.

Development of resistance of Escherichia coli to ampicillin. Six strains of ampicillin-sensitive Escherichia coli were subcultured on ampicillin ditch plates containing 50-200 $\mu \mathrm{g}$. ampicillin $/ \mathrm{ml}$. to determine the rate of development of resistance. The number of subcultures and the corresponding minimum inhibitory concentrations were recorded. A strain of $\boldsymbol{E}$. coli was also subcultured on nutrient agar plates containing ampicillin at 2.5-100 $\mu \mathrm{g} . / \mathrm{ml}$. Further tests were made to detect the presence of ampicillin-resistant mutants by using large inocula in broth. Nine ml. ampicillin-containing broth were added to $1 \mathrm{ml}$. of a $24 \mathrm{hr}$. broth culture of an ampicillin-sensitive strain of $E$. coli; ampicillin was used at 10, 25, 50 and $100 \mu \mathrm{g} . / \mathrm{ml}$., with 10 tubes for each concentration. The cultures were examined at $\mathbf{2}$ and $\mathbf{5}$ days for increased growth, the presence of resistant mutants and ampicillin inactivation. A known non-penicillinase-producing staphylococcus was used as a negative control.

The effect of inoculum size on grozth in ampicillin. Dilutions of $18 \mathrm{hr}$. broth cultures were made in sets of 8 tubes containing $5 \mathrm{ml}$. broth $+500 \mu \mathrm{g}$. ampicillin. The dilutions of the broth cultures were 10 fold, ranging from $1 / 10$ to $1 / 10^{8}$. The organisms tested were Proteus vulgaris, $\boldsymbol{P}$. rettgeri, Escherichia coli and a strain of penicillin-resistant Staphylococcus aureus. Control tubes containing $5 \mathrm{ml}$. broth only were inoculated in a similar manner with the staphylococcus. The cultures were incubated for $48 \mathrm{hr}$. at $37^{\circ}$ and the number of tubes which showed growth recorded. Residual ampicillin was assayed by the cup-plate method after incubation for $24 \mathrm{hr}$.

Comparison of ampicillin and benzylpenicillin as a substrate for penicillinase. The iodometric method was used to determine the relative amounts of penicilloic acid formed from ampicillin and benzylpenicillin when incubated with broth cultures of coliform bacilli or Staphylococcus aureus. Samples (0.5-2 ml.) of an $18 \mathrm{hr}$. shaken broth culture were incubated with $5 \mathrm{ml}$. of similar concentrations of ampicillin or benzyl penicillin $(0 \cdot 25 \mathrm{~g}$. in $100 \mathrm{ml}$. phosphate buffer, $\mathrm{pH} 6 \cdot 5)$. Three estimations were made on cultures of the Escherichia coli strain. Ampicillin and benzylpenicillin inactivation by the same strain of $E$. coli was also tested by the cup-plate assay 
method with antibiotic concentration $20 \mu \mathrm{g} . / \mathrm{ml}$. and an $18 \mathrm{hr}$. broth culture of organism.

Culture media. A beef digest broth (pH 7.4) was used in all experiments solidified with $1 \cdot 4 \%$ agar (Oxoid no. 2) when required.

\section{RESULTS}

Ampicillin sensitivity tests. The number of strains tested by the ditch-plate method which were sensitive to ampicillin is shown in Table 1 . This shows that 34/41 strains of Escherichia coli and 26/38 strains of Proteus mirabilis were sensitive to ampicillin. All other organisms tested were resistant apart from two strains of Klebsiella which were isolated from sputum (Klebsiella pneumoniae).

Ampicillin inactivation. The results of the screening test on ampicillin inactivation are also shown in Table 1. It can be seen that most of the organisms fall in one of two main groups; one group was able to inactivate ampicillin and the other group showed no detectable inactivation by this method. In the smaller, third group of organisms were eight strains of Proteus morganii and two strains of Citrobacter

Table 1. Screening test for ampicillin inactivation

\begin{tabular}{|c|c|c|c|c|c|}
\hline \multirow[b]{2}{*}{ Organism } & \multirow[b]{2}{*}{$\begin{array}{l}\text { Total } \\
\text { strains }\end{array}$} & \multirow{2}{*}{$\begin{array}{c}\text { No. of } \\
\text { strains } \\
\text { sensitive to } \\
\text { ampicillin }\end{array}$} & \multicolumn{3}{|c|}{$\begin{array}{c}\text { Inactivation of ampicillin } \\
(100 \mu \mathrm{g} \cdot / \mathrm{ml} \text {. in } 5 \mathrm{ml} \text {. of broth culture })\end{array}$} \\
\hline & & & Positive & $\overbrace{\text { Partial }}$ & $\overline{\text { Negative }}$ \\
\hline ichia coli I and II & 41 & $\mathbf{3 4}$ & 0 & $\mathbf{0}$ & 41 \\
\hline cter freundii & 6 & $\mathbf{0}$ & 4 & 2 & . \\
\hline ella I and II & 21 & $\mathbf{2}$ & 19 & $\mathbf{0}$ & 2 \\
\hline morganii & 12 & 0 & 2 & 8 & 2 \\
\hline abilis & 38 & 26 & 12 & $\mathbf{0}$ & 26 \\
\hline geri & 9 & $\mathbf{0}$ & $\mathbf{5}$ & 4 & $\mathbf{0}$ \\
\hline aris & 10 & 0 & 10 & $\mathbf{0}$ & 0 \\
\hline ence & $\mathbf{3}$ & $\mathbf{0}$ & $\mathbf{3}$ & $\mathbf{0}$ & 0 \\
\hline monas pyocyanea & 8 & $\mathbf{0}$ & 0 & $\mathbf{0}$ & 8 \\
\hline
\end{tabular}

Positive $=$ complete inactivation of ampicillin. Partial $=$ partial inactivation of ampicillin. Negative $=$ no detectable inactivation.

freundii, resistant or partially resistant to ampicillin and which showed partial inactivation of ampicillin. Seven of the Escherichia coli strains were resistant or partially resistant to ampicillin and showed no detectable inactivation. There were 26 strains of Proteus mirabilis and 2 strains of Klebsiella sensitive to ampicillin and all showed no detectable inactivation. Of 71 organisms (excluding Pseudomonas pyocyanea) which showed no detectable inactivation, 9 were resistant to ampicillin, whereas all strains which showed complete or partial inactivation were resistant to ampicillin. The results indicate that none of the $E$. coli or ampicillin-sensitive strains of $\boldsymbol{P}$. mirabilis actively destroyed ampicillin whereas most of the Klebsiella and ampicillin resistant strains of Proteus did.

The tests made with three strains of Escherichia coli incubated with smaller amounts of ampicillin showed that $E$. coli inactivated ampicillin slowly as compared with a strain of Klebsiella. The results of three tests for each organism are shown in Table 2. The strains of $E$. coli usually inactivated very little ampicillin after incubation for $6 \mathrm{hr}$. but completely inactivated $20 \mu \mathrm{g}$. ampicillin/ml. (in $5 \mathrm{ml}$. broth) 
after incubation for $18 \mathrm{hr}$. There were three exceptions: one test showed complete inactivation after $6 \mathrm{hr}$. and in two others there was little inactivation after $18 \mathrm{hr}$. A strain of Klebsiella inactivated $20 \mu \mathrm{g}$. ampicillin $/ \mathrm{ml}$., in one $\mathrm{hr}$. The four strains of ampicillin-sensitive Proteus mirabilis tested by the same method showed no clear evidence of inactivation as compared with a non-penicillinase-producing staphylococcus. This may have been due to the test not being sufficiently sensitive. Inactivation of ampicillin by Pseudomonas pyocyanea was also difficult to detect by the cup-plate assay method, as a zone of inhibition of the Oxford staphylococcus occurred with the control organism without added antibiotic. Similar experiments with $P$ s. pyocyanea by the iodometric method gave inconsistent results owing to clumping of the organisms. On several occasions there was evidence of ampicillin inactivation at $24 \mathrm{hr}$., but very little at $6 \mathrm{hr}$.

Table 2. Inactivation of ampicillin

(20 $\mu \mathrm{g} . / \mathrm{ml}$. in $5 \mathrm{ml}$. of broth culture.)



* Controls contained nutrient broth and ampicillin only.

Results of penicillinase estimations by the iodometric method. The relative amounts of penicillinase produced in overnight shaken broth cultures and estimated by the iodometric method are shown in Table 3 . The results show the amounts of penicilloic acid formed by $1 \mathrm{ml}$. broth culture from benzylpenicillin in $1 \mathrm{hr}$. when shaken at $37^{\circ}$. The results mainly confirm the cup-plate assay results. The Escherichia coli strains produced low amounts of penicillinase, and the ampicillin-sensitive strains of Proteus mirabilis (which are more sensitive to ampicillin than $E$. coli) produced just detectable amounts of penicillinase. The three strains of Proteus rettgeri and the two strains of Citrobacter freundii showed no inactivation or partial destruction by the screening test and by this test also seemed to show lower amounts of penicillinase than did the other ampicillin-resistant penicillinase producers. Apart from these strains, the ampicillin-resistant strains in general produced more than $1 \mu$ mole penicilloic acid $/ \mathrm{ml}$. culture/hr. under these conditions. A culture of a penicillinase-producing staphylococcus of comparable optical density gave a result two to three times higher than did the penicillinase-producing coliform organisms. The penicillinase produced 
under these conditions appears to be mainly intracellular. An overnight shaken broth culture of an ampicillin-resistant Klebsiella produced $1.9 \mu$ mole penicilloic acid $/ \mathrm{ml}$. broth culture $/ \mathrm{hr}$. and the supernatant fluid showed $0 \cdot 4 \mu \mathrm{mole} / \mathrm{ml} . / \mathrm{hr}$. An ampicillin-sensitive strain of Escherichia coli gave $0 \cdot 6 \mu$ mole penicilloic acid $/ \mathrm{ml}$. broth culture $/ \mathrm{hr}$. and the supernatant fluid $0 \cdot 17 \mu \mathrm{mole} / \mathrm{ml} . / \mathrm{hr}$.

Effect of $\mathrm{pH}$ value on penicillinase cultures. Maximum penicillinase activity occurred at $\mathrm{pH} 6.0$ with the strains of Klebsiella, Proteus vulgaris and Escherichia coli tested. Activity decreased slightly between $\mathrm{pH} \mathrm{6.0} \mathrm{and} \mathrm{7.0} \mathrm{but} \mathrm{decreased}$ rapidly between $\mathrm{pH} 6 \cdot 0$ and $5 \cdot 0$.

\section{Table 3. Penicillinase (iodometric method) activity}

\begin{tabular}{|c|c|c|c|}
\hline Organism & $\begin{array}{l}\text { No. of } \\
\text { strains }\end{array}$ & $\begin{array}{l}\text { Ampicillin } \\
\text { sensitivity }\end{array}$ & $\begin{array}{l}\text { Penicillinase activity } \mu \text { mole peni- } \\
\text { cilloic acid/ml. of broth culture } 1 \mathrm{hr}\end{array}$ \\
\hline Escherichia coli & $\mathbf{5}$ & Sensitive & $0 \cdot 55,0 \cdot 34,0 \cdot 42,0 \cdot 45,0 \cdot 46$ \\
\hline E. coli & 1 & Resistant & $0 \cdot 47$ \\
\hline Citrobacter & $\mathbf{2}$ & Resistant & $1 \cdot 15,0 \cdot 75$ \\
\hline Klebsiella & 6 & Resistant & $1 \cdot 6,1 \cdot 8,2 \cdot 6,2 \cdot 4,1 \cdot 6,2 \cdot 0$ \\
\hline \multirow[t]{2}{*}{ Proteus mirabilis } & $\mathbf{3}$ & Sensitive & $0 \cdot 16,0 \cdot 18,0 \cdot 23$ \\
\hline & 2 & Resistant & $3 \cdot 15,2 \cdot 16$ \\
\hline P. rettgeri & 3 & Resistant & $0 \cdot 7,0 \cdot 9,0 \cdot 63$ \\
\hline P. morganii & $\mathbf{3}$ & Resistant & $3 \cdot 05,2 \cdot 35,1 \cdot 9$ \\
\hline P. vulgaris & $\mathbf{3}$ & Resistant & $1 \cdot 7,2 \cdot 9,1 \cdot 3$ \\
\hline Staphylococcus aureus & $\mathbf{1}$ & Resistant & $9 \cdot 4$ \\
\hline S. aureus & 1 & Sensitive & $0 \cdot 08,0 \cdot 05,0 \cdot 06,0 \cdot 2,0 \cdot 11,0 \cdot 14$ \\
\hline
\end{tabular}

Table 4. Induction of penicillinase

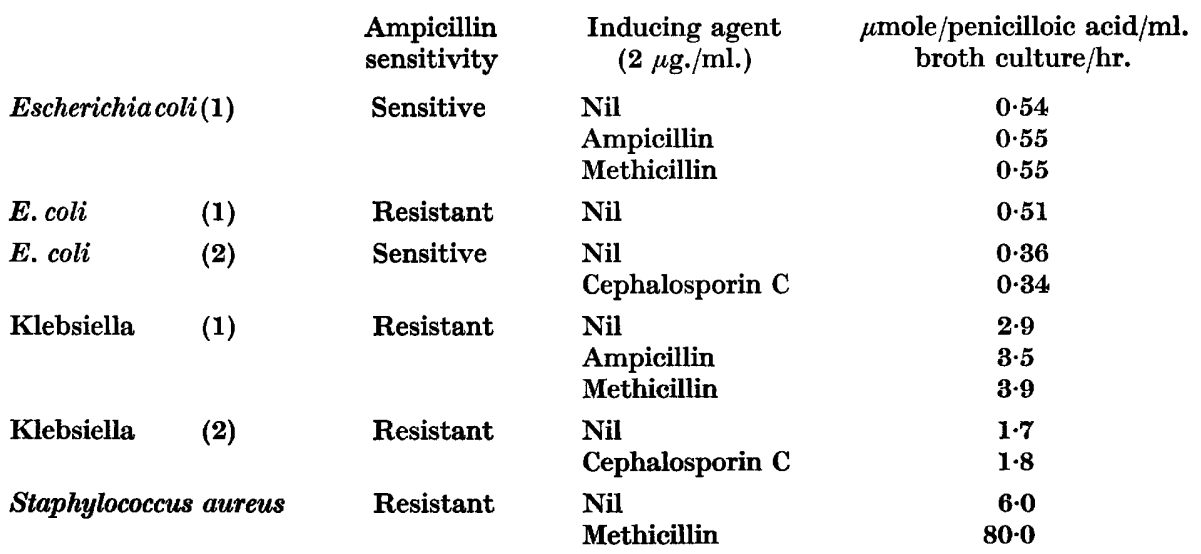

Induction of penicillinase. The results of penicillinase values obtained with $6 \mathrm{hr}$. shaken broth cultures to which had been added ampicillin, methicillin or cephalosporin $\mathrm{C}$ are shown in Table 4. The optical density of the cultures was about the same and, in the results shown, the values had been corrected to the same optical density for each organism examined. The cultures were incubated for $5 \mathrm{hr}$. with benzylpenicillin for the Escherichia coli strains and for $1 \mathrm{hr}$. for the Klebsiella strains and the strain of Staphylococcus aureus. A penicillinase-producing strain of $S$. aureus was included to show the effect of methicillin on the penicillinase level under similar cultural conditions. The results show that there was no significant increase in penicillinase 
values in the strains of Klebsiella, or $E$. coli examined in the presence of the three possible inducing agents tested. This was in marked contrast to the large increase in penicillinase when the penicillin-resistant staphylococcus was grown in presence of methicillin.

Amidase production. In tests at $37^{\circ}$ none of the 49 strains which inactivated ampicillin gave positive evidence of the production of penicillin amidase; this suggests that the inactivating enzyme was a $\beta$-lactamase, which was confirmed by the iodometric method. The 60 ampicillin-sensitive strains also showed no evidence of amidase production at $37^{\circ}$. When organisms of broth cultures grown at $28-30^{\circ}$ were incubated with penicillin at $\mathrm{pH} 8.0$ similar negative results were obtained with all strains apart from the known amidase-producing strain of Escherichia coli.

Development of resistance of Escherichia coli to ampicillin. Resistance developed rapidly when six strains of ampicillin-sensitive Escherichia coli were subcultured on nutrient agar plates containing ampicillin. There was a 20-40-fold increase in resistance after 6-8 subcultures. No difference in ampicillin inactivation was seen as between the sensitive and resistant strains by the cup-plate method; this was confirmed by the iodometric method. The result with one strain is shown in Table 4 (E. coli (1)), ampicillin-sensitive and resistant).

When a heavy inoculum of a strain of ampicillin-sensitive Escherichia coli was grown on ampicillin-containing agar plates, the minimum inhibitory concentration after incubation for $24 \mathrm{hr}$. was $2 \cdot 5-5 \cdot 0 \mu \mathrm{g}$. ampicillin $/ \mathrm{ml}$. After several days at room temperature large and small colonies appeared on the plate containing $5 \cdot 0 \mu \mathrm{g}$. ampicillin $/ \mathrm{ml}$. Although both types of colony grew normally on nutrient agar, the minimum inhibitory concentration for the larger colonies was $12.5 \mu \mathrm{g}$. ampicillin/ ml., whereas the resistance of the small colonies was unchanged. After 5 subcultures of the larger colonies, the resistance increased to $100 \mu \mathrm{g}$. ampicillin $/ \mathrm{ml}$. This confirms that resistance develops rapidly in a step-wise manner.

The tests with heavy inocula in broth cultures containing ampicillin showed no evidence of any highly resistant single-step mutants when subcultured on ampicillin plates; growth occurred in 10 to $\mathbf{5 0} \mu \mathrm{g}$. ampicillin $/ \mathrm{ml}$., after incubation for 5 days. This appeared to be due to slow inactivation of ampicillin, since ampicillin activity was only detected in the tubes of broth containing $100 \mu \mathrm{g}$. ampicillin $/ \mathrm{ml}$., and there was no increased growth at this concentration. There was no comparable inactivation in cultures of a non-penicillinase-producing staphylococcus, under similar cultural conditions.

\section{The effect of inoculum size on growth in ampicillin}

The results of growth with different inoculum sizes in broth containing $100 \mu \mathrm{g}$. ampicillin $/ \mathrm{ml}$. are shown in Table 5. The approximate penicillinase activity is shown in the last column. The strain of Staphylococcus aureus, although apparently producing more penicillinase than the Proteus or Klebsiella strains, did not grow when the inoculum was diluted $1 / 10^{5}$. The Klebsiella and Proteus strains grew when the inoculum was diluted $1 / 10^{8}$; no residual ampicillin was detected at this dilution with these organisms after incubation for $24 \mathrm{hr}$. There was no significant inactivation of ampicillin in the tube containing $S$. aureus at dilutions of inocula from $1 / 10^{5}$ to $1 / 10^{8}$. There was no detectable inactivation with the $E$. coli strain at any dilution of inoculum. 
Penicillinase activity on ampicillin and benzylpenicillin. The amounts of penicilloic acid formed by coliform bacilli and by Staphylococcus aureus from ampicillin and benzylpenicillin are shown in Table 6. Penicilloic acid formed from ampicillin by Proteus mirabilis, Klebsiella and $S$. aureus was about the same or rather more than from benzylpenicillin. The three tests made with ampicillin-sensitive Escherichia coli showed that less penicilloic acid was formed from ampicillin than from benzylpenicillin. The cup-plate assay result also confirmed that ampicillin was inactivated less rapidly than benzylpenicillin by $\boldsymbol{E}$. coli.

Table 5. The effect of inoculum size on groroth in ampicillin

$\begin{array}{llcc}\text { Ompicillin } & \begin{array}{c}\text { Dilution of inoculum } \\ \text { showing growth in } \\ \text { broth containing } \\ \text { Organism }\end{array} & \begin{array}{c}\text { Penicillinase } \\ \text { ampicillin after }\end{array} & \begin{array}{c}\text { activity } \mu \text { mole } \\ \text { penicilloic } \\ \text { acid/ml. } \\ \text { of broth } \\ \text { culture/hr. }\end{array} \\ \text { Klebsiella } & \begin{array}{c}\text { Am hr. incubation } \\ \text { sensitivity }\end{array} & 10^{-8} & \mathbf{2 \cdot 9} \\ \text { Proteus vulgaris } & \text { Resistant } & 10^{-8} & \mathbf{2 \cdot 9} \\ \text { P. rettgeri } & \text { Resistant } & 10^{-8} & \mathbf{0 \cdot 7} \\ \text { Escherichia coli } & \text { Resistant } & <10^{-1} & 0 \cdot 5 \\ \text { Staphylococcus aureus } & \text { Sensitive } & 10^{-4} & \mathbf{8 \cdot 2}\end{array}$

Table 6. Penicillinase activity on ampicillin and benzylpenicillin

\begin{tabular}{|c|c|c|c|}
\hline \multirow[b]{2}{*}{ Organism } & \multirow[b]{2}{*}{$\begin{array}{l}\text { Ampicillin } \\
\text { sensitivity }\end{array}$} & \multicolumn{2}{|c|}{$\begin{array}{c}\text { Penicillinase activity } \\
\mu \text { mole penicilloic acid } / \mathrm{ml} \text {. } \\
\text { of broth culture } / \mathrm{hr} \text {. }\end{array}$} \\
\hline & & Ampicillin & $\begin{array}{c}\text { Benzyl- } \\
\text { penicillin }\end{array}$ \\
\hline Proteus mirabilis & Resistant & $\mathbf{1 . 5}$ & 0.86 \\
\hline Klebsiella & Resistant & $1 \cdot 6$ & $1 \cdot 4$ \\
\hline \multirow[t]{3}{*}{ Escherichia coli } & Sensitive & $0 \cdot 16$ & $0 \cdot 6$ \\
\hline & & $0 \cdot 11$ & $0 \cdot 54$ \\
\hline & & $0 \cdot 1$ & $0 \cdot 4$ \\
\hline Staphylococcus aureus & Resistant & 9.0 & $4 \cdot 2$ \\
\hline
\end{tabular}

\section{DISCUSSION}

By the not very sensitive cup-plate method used as a screening test for ampicillin inactivation, there was a clear correlation between resistance to ampicillin and its inactivation by most of the strains tested Citrobacter, Klebsiella and the Proteus groups. This correlation was not seen with the strains of Escherichia coli, none of which showed ampicillin inactivation by this test, although 7 of the 41 strains tested were resistant to ampicillin. None of the strains of Pseudomonas pyocyanea gave positive evidence of ampicillin inactivation although all strains of this species are resistant to ampicillin. Similar results were obtained by Trafford et al. (1962) with Klebsiella and a smaller number of strains of $E$. coli, but they described four strains of ampicillin-resistant Proteus mirabilis which did not produce penicillinase. By the iodometric method, however, it was found that the strains of $E$. coli did in fact produce some penicillinase, whether they were sensitive to ampicillin or not, although the values were lower than those of the ampicillin-resistant strains of 
Proteus, Klebsiella or penicillin-resistant Staphylococcus aureus. Ampicillinsensitive strains of $\boldsymbol{P}$. mirabilis seemed to show even lower values of penicillinase than did the $E$. coli strains.

Ampicillin was inactivated as rapidly, or more rapidly than benzylpenicillin by the ampicillin-resistant strains of Proteus, Klebsiella and Staphylococcus aureus. However, it was also shown that ampicillin was more resistant than benzylpenicillin to penicillinase produced by a strain of Escherichia coli. This suggests that the penicillinase produced by this $E$. coli strain differs from that produced by the strains of Proteus, Klebsiella or $S$. aureus. This difference in resistance of the two antibiotics to penicillinase corresponds to the difference in sensitivity of $E$. coli to ampicillin and benzylpenicillin.

The experiments described here suggest that there is no marked increase in penicillinase production by coliform bacilli grown in presence of low concentrations of ampicillin, methicillin or cephalosporin $\mathrm{C}$. This contrasts with other penicillinaseproducing organisms such as Staphylococcus aureus (Geronimus \& Cohen, 1957) and Bacillus cereus (Pollock, 1950). No evidence of penicillin-amidase production was found for the strains examined under the conditions described. Some degree of amidase production cannot be excluded since many of the organisms also produce penicillinase which splits the $\beta$-lactam ring. The resistance of naturally-occurring strains of $S$. aureus to penicillin is considered to be almost entirely due to penicillinase production. In the experiments here described with inocula of different sizes, the strain of $S$. aureus was inhibited by $100 \mu \mathrm{g}$. ampicillin $/ \mathrm{ml}$. when the inoculum was diluted $1 / 10^{5}$, whereas with the strains of Proteus and Klebsiella, although they apparently produced less penicillinase, an inoculum diluted $1 / 10^{8}$ grew in this concentration of ampicillin. It therefore seems unlikely that the resistance of these strains to ampicillin depends solely on penicillinase production.

I wish to thank Beecham Research Laboratories Ltd., for a grant which made this research possible, Dr Mary Barber and Dr R. Novick, for advice and criticism and Mrs J. Filbey for technical assistance.

\section{REFERENCES}

Abraham, E. P. \& Chain, E. (1940). An enzyme from bacteria able to destroy penicillin. Nature, Lond. 146, 837.

Bondi, A. \& Dietz, C. C. (1944). Production of penicillinase by bacteria. Proc. Soc. exp. Biol., N.Y. 56, 132.

Brumfitt, W., Percival, A. \& Carter, M. J. (1962). Treatment of urinary tract infections with ampicillin. Lancet, $\mathrm{i}, 130$.

Czekalowski, J. W. (1950). Penicillin inactivators of bacterial origin. J. Path. Bact. 62, 85.

Geronimus, L. H. \& Cohen, S. (1957). Induction of staphylococcal penicillinase. J. Bact. 73, 28.

HARPER, G. J. (1943). Inhibition of penicillin in routine culture media. Lancet, ii, 569.

Perret, C. J. (1954). Iodometric assay of penicillinase. Nature, Lond. 174, 1012.

Pollock, M. R. (1950). Penicillinase adaptation in B. cereus: Adapative enzyme formation in the absence of free filtrate. Brit. J. exp. Path. 31, 739.

Rolinson, G. N., Batchelor, F. R., Butterworth, D., Cameron-Wood, J., Cole, M., Eustace, G. C., Hart, M. V., Richards, M. \& Chain, E. B. (1960). Formation of 6aminopenicillanic acid from penicillin by enzyme hydrolysis. Nature, Lond. 187, 236. 
Rolinson, G. N. \& Stevens, S. (1961). Microbiological studies on a broad-spectrum penicillin, 'Penbritin'. Brit. med. J. ii, 191.

Stewart, G. T., Coles, H. M. T., Nixon, H. H. \& Holt, R. J. (1961). 'Penbritin': an oral penicillin with broad-spectrum activity. Brit. med. J. ii, 200.

Trafford, J. A. P., Maclaren, D. M., Lillicrap, D. A., Barnes, R. D. S., Houston, J. C. \& KNox, R. (1962). Ampicillin, a broad-spectrum pencillin. Lancet, i, 987.

URI, J. \& SztaricskaI, F. (1961). Simple, quick methods for detection of 6-aminopenicillanic acid. Nature, Lond. 191, 1223.

Woodruff, H. B. \& Foster, J. W. (1945). Microbiological aspects of pencillin. VII. Bacterial penicillinase. J. Bact. 49, 7. 